\title{
ANALISIS SEBARAN TENAGA KESEHATAN PUSKESMAS DI INDONESIA BERDASARKAN PERATURAN MENTERI KESEHATAN NOMOR 75 TAHUN 2014 TENTANG PUSKESMAS
}

\author{
Yuni Sari Romadhona ${ }^{\bowtie}$, Kemal N. Siregar \\ Fakultas Kesehatan Masyarakat Universitas Indonesia
}

\section{ARTICLE INFO \\ Article history \\ Submitted : 2018-09-28 \\ Revised : 2018-12-09 \\ Accepted : 2018-12-28}

\section{Keywords:}

Health Workers

Public Health Centre

Maldistribution

Inequality

\begin{abstract}
The persistent problem faced by Indonesia is in adequate in number and maldistribution of health workers in Primary Health Centre (PHC) has resulted in disrupted health services to the community. The aims of this study is describe health workers in ratio PHC per 100,000 population and health workers distributionbyregions. This research is descriptive analytic. The data used are secondary data from the health workers in government health care facilities in the district/city and province in Indonesia collected by Sub Centre data and information of health ministry in June 2018 and analyzed using the chi-square. The fact that inadequate numbers and maldistributionare remaining problems of health workers in PHC. The ratio of physiciansis 10,17, midwifes 84,73, nurses 83, Public health services 11,09 and nutritionists 8,30 per 100,000 populations while Government standards are higher. Maldistributions of health workers in PHC occurred in central and east regions of Indonesia. The highest number of health workers at PHC in Indonesian is midwives and nurses, while the smallest workforce is dentists. As in adequate numbers and maldistribution are the remaining problems of health workers in PHC, the recruitment of health workers should fulfil the community needs, geographic and avalaibility of health services. Providing the government scholarship to the locals in health schools with commitment to work for local government after graduation is one of the solution for this problem. E-health service is another solution, health service consultation can be carried out effectively and efficiently with remote health experts by taking the advantage of the internet.
\end{abstract}

Corresponding Author:

Yuni Sari Romadhona

Fakultas Kesehatan Masyarakat Universitas Indonesia

Telp. 08128344802

Email: yunisari.rd@gmail.com

\section{PENDAHULUAN}

Puskesmas sebagai Gatekeeper sistem pelayanan kesehatan dimana fasilitas kesehatan tingkat pertama yang berperan sebagai pemberi pelayanan kesehatan dasar berfungsi optimal sesuai standar kompetensinya dan memberikan pelayanan kesehatan sesuai standar pelayanan medik. Bentuk pelayanan yang dilakukan kepada masyarakat berupa palayanan promotif, preventif, kuratif dan rehabilitatif selain itu Puskesmas juga memiliki peran yang sangat penting dalam membentuk sistim kesehatan nasional di Indonesia (BPJS, 2016) (Wulandari \& Achadi, 2016).

Tenaga Kesehatan di Puskemas merupakan ujung tombak dalam menyediakan dan penyelenggara pelayanan kesehatan di tingkat dasar kepada masyarakat. Dalam memberikan pelayanan kesehatan yang optimal kepada masyarakat, puskesmas perlu didukung oleh tenaga kesehatan yang mencukupi baik dari segi jumlah maupun kualitas.

Tenaga kesehatan menurut UndangUndang Kesehatan Nomor 36 Tahun 2009 adalah seseorang yang memiliki ilmu pengetahuan, keterampilan dan izin untuk melakukan tindakan atau upaya kesehatan serta bersedia mengabdikan diri kepada masyarakat pada bidang kesehatan (Indonesia, 2009) (Indonesia, 2014b). Sedangkan berdasarkan Peraturan Menteri Kesehatan Nomor 75 Tahun 2014 menyebutkan bahwa tenaga kesehatan 
yang bekerja berdasarkan standar ketenagaan di Puskesmas minimal memiliki 9 jenis tenaga kesehatan (Kemenkes Republik Indonesia, 2014).

Ratio dokter umum Tahun 2017 sebesar 45 per 100,000 penduduk, ratio perawat sebesar 170 per 100,000 penduduk dan ratio bidan adalah sebesar 162 per 100.000 penduduk di Indonesia (Kepala Badan PPSDM Kesehatan, 2017). Sedangkan Kondisi tenaga kesehatan di Puskesmas Tahun 2017 menurut Badan Pengembangan dan Pemberdayaan Sumber Daya Manusia Kesehatan, berdasarkan standar minimal ketenagakerjaan mengalami kekurangan tenaga kesehatan sebesar 49,632 orang, dan mengalami distribusi tenaga kesehatan yang tidak merata (maldistribution) sebesar 155,833 orang tenaga kesehatan di Puskesmas Indonesia(Kepala Badan PPSDM Kesehatan, 2017). Rencana strategis tenaga kesehatan 2011 - 2025 menyebutkan bahwa bila dilihat dari rasio jumlah dan distribusi tenaga kesehatan di Indonesia, maka saat ini negara kita belum mencapai target yang telah ditetapkan (Kemenkes Republik Indonesia, 2011).

Masih ada Puskesmas yang tenaga kesehatannya berdasarkan jenisnya belum memenuhi standar, sehingga dibutuhkan perencanaan dan pengadaan tenaga kesehatan yang adekuat dari setiap satuan unit kerja. Beberapa puskesmas tidak memiliki tenaga kesehatan misalnya Dokter gigi, atau petugas ahli teknologi laboratorium medik, tetapi berlebih tenaga kesehatan seperti Dokter umum, perawat dan bidan(Mujiyati, 2016). Provinsi di Indonesia yang masih mengalami kekurangan dokter umum, perawat dan bidan adalah Papua, Papua Barat, Nusa Tenggara Timur, Nusa Tenggara Barat, Maluku, Kalimantan Timur (Budijanto, 2015).

Metode yang digunakan dalam menyusun kebutuhan tenaga kesehatan adalah menggunakan rasio terhadap nilai tertentu (methode ratio) (Kurniati, 2017). Dalam memberikan pelayanan kesehatan kepada masyarakat secara merata pemerintah mengatur masalah penempatan tenaga kesehatan berdasarkan kebutuhan masyarakat, jenis sarana dan prasarana yang tersedia dan beban kerja tenaga kesehatan yang telah tersedia di suatu daerah (Kemenkes Republik Indonesia, 2014) (Indonesia, 2009) (Kemenkes Republik Indonesia, 2010).
Masalah klasik yang dihadapi Indonesia dalam upaya mewujudkan pelayanan kesehatan adil dan merata bagi masyarakat adalah ketersediaan tenaga kesehatan pada tingkat pelayanan dasar yang tidak merata jumlah dan pesebarannya di Puskesmas. Penelitian yang dilakukan di Puskesmas Pembantu Linggang Amer Kecamatan Linggang Bigung Kabupaten Kutai Barat menyebutkan bahwa faktor yang menghambat pelayanan kesehatan pada masyarakat adalah tidak adanya tenaga kesehatan Dokter dan kurangnya sarana dan prasarana dalam menunjang pelayanan kesehatan (Nurhayati, 2016).

Tujuan penelitian ini adalah untuk melihat gambaran tenaga kesehatan di Puskesmas Indonesia berdasarkan ratio jumlah penduduk dan penyebarannya berdasarkan pembagian wilayah Indonesia bagian barat, tengah dan timur.

\section{METODE PENELITIAN Jenis Penelitian}

Penelitian ini merupakan penelitian deskriptif analitik dengan desain non eksperimental (cross sectional), dengan tujuan untuk melihat frekuensi dan distribusi tenaga kesehatan di Puskesmas berdasarkan rasio jumlah penduduk dan pembagian wilayah Indonesia.

\section{Pengumpulan Data}

Data yang diolah dalam penelitian ini adalah data sekunder tenaga kesehatan dari fasilitas pelayanan kesehatan milik pemerintah di wilayah kabupaten/Kota dan Provinsi di Indonesia, yang bersumber dari Sub Bagian Data dan Informasi Badan Pengembangan dan Pemberdayaan Sumber Daya Manusia Kesehatan, pada bulan Juni 2018.

\section{Analisa Data}

Data dianalisis dengan menggunakan program SPPS versi 24. Analisis bivariat dalam penelitian ini menggunkana chi square untuk melihat frekuensi dan nilai tengah (mean) jumlah tenaga kesehatan di Puskesmas terhadap jumlah peduduk dan pembagian wilayah di Indonesia.

\section{HASIL PENELITIAN}

Tenaga Kesehatan di Fasilitas Pelayanan Kesehatan Indonesia

Indonesia dengan jumlah Penduduk sebesar 261.900.000 dan luas wilayah 
1.916.862,20 $\mathrm{km}^{2}$ terdiri dari daratan dan lautan, dengan total fasilitas pelayanan kesehatan sebanyak 17.919 unit (BPS, 2018)

(Kemenkes Republik Indonesia, 2016).

\begin{tabular}{|c|c|c|c|c|c|}
\hline 400000 & & & & & Perawat \\
\hline $\begin{array}{l}300000 \\
250000 \\
200000\end{array}$ & & & & & $\stackrel{B}{B i d a n}$ \\
\hline 150000 & & & & & Nakes Lain \\
\hline $\begin{array}{l}100000 \\
50000\end{array}$ & & & & & $\begin{array}{l}\text { Farmasi } \\
\text { Dokter Umum } \\
\text { Dokter Gigi }\end{array}$ \\
\hline 0 & 2013 & 2014 & 2015 & 2016 & 2017 \\
\hline -Dokter Umum & 41841 & 42265 & 41026 & 41898 & 45387 \\
\hline - Dokter Gigi & 11857 & 13092 & 12740 & 13435 & 14707 \\
\hline Perawat & 288405 & 295508 & 223910 & 296876 & 345291 \\
\hline$\longrightarrow$ Bidan & 137110 & 136606 & 111736 & 163541 & 198110 \\
\hline Farmasi & 40181 & 46336 & 30329 & 38829 & 45843 \\
\hline Nakes lain & 125494 & 125349 & 179580 & 133131 & 135018 \\
\hline
\end{tabular}

\section{Grafik 1. Distribusi Tenaga Kesehatan di Fasilitas Pelayanan Kesehatan Indonesia Tahun} $2013-2017$

Berdasarkan grafik di atas, sejak Tahun 2013 sampai dengan Tahun 2017 terjadi kenaikanjumlah tenaga kesehatan yang didayagunakan di fasilitas pelayanan Indonesia, namun hal tesebut belum diimbangi dengan persebaran tenaga kesehatan secara merata, sehingga masalah kekurangan jumlah dan sebaran tenaga kesehatan masih menjadi masalah sampai saat ini. Berdasarkan data di atas jumlah tenaga kesehatan dengan jumlah terbesar adalah Perawat sebanyak 345.291 orang, dan Bidan 198.110 orang, sedangkan tanaga kesehatan dengan jumlah terkecil adalah Dokter Gigi yaitu sebanyak 14.707 orang.

\section{Tenaga Kesehatan di Puskesmas Indonesia}

Peraturan Meneteri Kesehatan Nomor 75 tahun 2014 menyebutkan standar tenaga kesehatan di Puskesmas Indonesia terdiri dari sembilan yang terdiri dari dokter umum, dokter gigi, perawat, bidan, petugas kesehatan masyarakat, petugas kesehatan lingkungan, petugas farmasi, petugas gizi, dan petugas, ahli teknologi laboratorium medik (ATLM). Jumlah Puskesmas sebanyak 10.272 unit yang tersebar diseluruh wilayah Indonesia (Kemenkes Republik Indonesia, 2018).
Total tenaga kesehatan di Puskesmas Indonesia terdiri dari; Dokter Umum 18.548 $(5,13 \%)$ dengan rerata ratio sebesar 10,17 per penduduk. Dokter Gigi 7.320 (2,02\%) dengan rerata ratio sebesar 3,58 per 100.000 penduduk. Dokter Gigi $7.320(2,02 \%)$ rerata ratio sebesar 3,58 per 100.000 penduduk. Perawat 7.320 $(2,02 \%)$ dengan rerata ratio sebesar 3,58 per 100.000 penduduk. Bidan sebanyak 153.707 $(42,58 \%)$, nilai rerata ratio sebesar 84,73 per 100.000 penduduk. Petugas kesehatan Masyarakat $14,53(4,02 \%)$, nilai rerata ratio sebesar 11,09 per 100.000 penduduk. Petugas kesehatan Lingkungan 10.619 (2,94\%), dengan rerata ratio sebesar 7,21 per 100.000 penduduk. Petugas kesehatan Farmasi 12.663 (3,50\%), dengan nilai rerata ratio sebesar 7,99 per 100.000 penduduk. Petugas kesehatan Gizi sebanyak $11,116(3,09 \%)$, nilai rerata ratio sebesar 8,30 per 100.000 penduduk. Petugas ATLM $8.516(2,35 \%)$, dengan nilai rerata ratio sebesar 5,17 per 100,000 penduduk.

Tenaga kesehatan di Puskesmas Wilayah Indonesia Bagian Barat terbanyak adalah bidan yaitu $114.123((74,24 \%)$ dengan rerata ratio sebesar 16,45 per 100.000 penduduk, sedangkan tenaga kesehatan tersedikit adalah Dokter Gigi yaitu 5.425 
$(74,11 \%)$ dengan rerata ratio sebesar 0,80 per 100,000 penduduk.

Tenaga Kesehatan yang didayagunakan di Puskesmas Wilayah Indonesia Bagian Tengah dan memiliki angka terbanyak adalah bidan yaitu $34.126(22,20 \%)$ dengan rerata ratio sebesar 13,78 per 100.000 penduduk, sedangkan tenaga kesehatan tersedikit adalah Dokter Gigi yaitu $1.753(23,94 \%)$ dengan rerata ratio sebesar 0,73 per 100.000 penduduk.

Tabel 1. Distribusi Jumlah, Persentase dan Rerata Ratio Per 100,000 Penduduk Tenaga Kesehatan di Puskesmas Indonesia Berdasarkan Jenis dan Pembagian Wilayah di Indonesia, Per Juni 2018

\begin{tabular}{|c|c|c|c|c|}
\hline \multirow{4}{*}{$\begin{array}{c}\text { Jenis Tenaga } \\
\text { Kesehatan }\end{array}$} & \multicolumn{3}{|c|}{ Indonesia } & \multirow{4}{*}{$\begin{array}{c}\text { Total } \\
(\%) \\
\bar{x}\end{array}$} \\
\hline & Barat & Tengah & Timur & \\
\hline & Jumlah & Jumlah & Jumlah & \\
\hline & $\frac{(70)}{x}$ & $\bar{x}$ & $\frac{1}{x}$ & \\
\hline \multirow{3}{*}{ Dokter Umum } & 13699 & 4135 & 714 & 18548 \\
\hline & $(72.85)$ & $(22.29)$ & $(3,84)$ & $(513 \%)$ \\
\hline & 2,21 & 1,77 & 0,74 & 10,17 \\
\hline \multirow{3}{*}{ Dokter Gigi } & 5,425 & 1,753 & 142 & 7.320 \\
\hline & $(74,11)$ & $(23,94)$ & $(1,93)$ & $(2,02 \%)$ \\
\hline & 0,80 & 0,73 & 0,16 & 3,58 \\
\hline \multirow{3}{*}{ Perawat } & 80,886 & 33,491 & 9,513 & 123,890 \\
\hline & $(65,28)$ & $(27,03)$ & $(7,67)$ & $(34,32 \%)$ \\
\hline & 12,57 & 13,71 & 10.17 & 83,00 \\
\hline \multirow{3}{*}{ Bidan } & 114,123 & 34,126 & 5,458 & 153,707 \\
\hline & $(74,24)$ & $(22,20)$ & $(7,67)$ & $(42,58 \%)$ \\
\hline & 16,45 & 13,78 & 6,28 & 84,73 \\
\hline \multirow{3}{*}{$\begin{array}{l}\text { Kesehatan } \\
\text { Masyarakat }\end{array}$} & 8,700 & 4,793 & 1,041 & 14,534 \\
\hline & $(59,85)$ & $(32,97)$ & $(7,16)$ & $(4,02 \%)$ \\
\hline & 1,41 & 1,88 & 1,22 & 11,09 \\
\hline \multirow{3}{*}{$\begin{array}{l}\text { Kesehatan } \\
\text { Lingkungan }\end{array}$} & 6,234 & 3,727 & 658 & 10,619 \\
\hline & $(58,70)$ & $(35,09)$ & $(6,19)$ & $(2,94 \%)$ \\
\hline & 0,97 & 1,48 & 0,71 & 7,21 \\
\hline \multirow{3}{*}{ Farmasi } & 8,391 & 3,658 & 614 & 12,663 \\
\hline & $(66,26)$ & $(28,88)$ & $(4,84)$ & $(3,50 \%)$ \\
\hline & 1,30 & 1,50 & 0,69 & 7,99 \\
\hline \multirow{3}{*}{ Gizi } & 6,263 & 3,977 & 926 & 11,116 \\
\hline & $(56,08)$ & $(35,61)$ & $(8,29)$ & $(3,09 \%)$ \\
\hline & 0,99 & 1,59 & 1,07 & 8,30 \\
\hline \multirow{3}{*}{ ATLM } & 5,743 & 2,273 & 500 & 8,516 \\
\hline & $(67,43)$ & $(26,69)$ & $(5,87)$ & $(2,35 \%)$ \\
\hline & 0,92 & 0,87 & 0,50 & 5,17 \\
\hline
\end{tabular}

Jumlah tenaga kesehatan terbanyak di Puskesmas Indonesia bagian Timur adalah Perawat yaitu $9.513(7,67 \%)$ dengan rerata ratio sebesar 10.17 per 100.000 penduduk, sedangkan tenaga kesehatan tersedikit adalah Dokter Gigi 142 (1,93\%) dengan rerata ratio sebesar 0,16 per 100.000 penduduk.

$\begin{array}{cccc}\text { Hasil } & \text { analisis } & \text { data } & \text { diatas } \\ \text { menggambarkan } & \text { bahwa } & \text { kondisi } & \text { tenaga }\end{array}$ kesehatan di Puskemas Indonesia masih mengalami ketidakmerataan (inequality) dalam jumlah dan penyebarannya, nampak bahwa distribusi tenaga kesehatan yang bekerja di Puskesmas wilayah Indonesia barat, tengah dan timur belum merata. Faktor jumlah penduduk yang tidak merata penyebarannya dan kondisi geografis turut berpengaruh dalam ketidakmerataan tenaga kesehatan. Daerah 
perkotaan cenderung banyak penduduk dan tanaga kesehatan sedangkan daerah pedesaan sebaliknya.

\section{PEMBAHASAN}

Sumber daya manusia kesehatan merupakan hal yang penting, karenanya dibutuhkan sumber daya manusia yang profesional dan berkualitas dalam pelaksanaan suatu sistem kesehatan, sehingga tujuan pembangunan kesehatan dapat tercapai. Sistem kesehatan nasional dilaksanakan secara berjenjang oleh Pemerintah Pusat dan Pemerintah Daerah disesuaikan dengan kewenangan Daerah dan kewenangan bidang kesehatan (Indonesia, 2012), namun kenyataan masalah sumber daya manusia sampai saat ini masih kurang diperhatikan, dibutuhkan perubahan pola pikir bahwa sumber daya manusia adalah suatu hal yang penting dalam pembangunan kesehatan dan pengelolaan sistem kesehatan nasional.

\section{Kekurangan Jumlah Tenaga Kesehatan di Puskesmas Indonesia}

Jumlah tenaga kesehatan di Puskesmas Indonesia saat ini belum dapat mencukupi target yang telah ditetapkan oleh Pemerintah, dan belum dapat memenuhi kebutuhan masyarakat, bahkan beberapa jenis tenaga kesehatan tidak tersedia di beberapa Puskesmas di Indonesia.

Mengacu pada Permenkes Nomor 75 Tahun 2014, dilihat dari jumlah minimal tenaga kesehatan di Puskesmas rawat inap maka dibutuhkan Dokter umum sebanyak dua orang, tujuh orang Bidan, delapam Perawat, dua Tenaga Kesehatan Masyarakat dan dua Tenaga Kesehatan Gizi, sedangkan untuk Puskesmas Rawat Jalan jumlah minimal tenaga kesehatannya adalah satu Dokter umum, empat Bidan, lima Perawat, satu Tenaga Kesehatan Masyarakat dan satu Tenaga Kesehatan Gizi (Kemenkes Republik Indonesia, 2014). Sedangkan berdasarkan rancangan pengembangan tenaga kesehatan strategis Tahun 2011 - 2025 disebutkan bahwa standar tenaga kesehatan di Indonesia dibutuhkan; tenaga dokter spesialis sebanyak 24 orang, 96 dokter umum, 11 dokter gigi, 158 perawat, 75 bidan, 20 petugas sanitarian, dan 48 petugas gizi per 100,000 orang penduduk pada Tahun 2019 (Kemenkes Republik Indonesia, 2011).
Undang-undang Nomor 36 Tahun 2014 tentang tenaga kesehatan menyebutkan bahwa pemerintah bertanggung jawab dalam perencanaan, pengadaan dan pendayagunaan dengan melakukan pemerataan, pemanfaatan dan pengembangan tenaga kesehatan (Indonesia, 2014b). Sedangkan jumlah dan jenis tenaga kesehatan yang didayagunakan di Puskesmas dihitung berdasar pada beban kerja dengan memperhatikan jumlah penduduk dan persebarannya, luas wilayah daerah dan ketersediaan fasilitas pelayanan kesehatan (Kemenkes Republik Indonesia, 2014). Menurut Anna Kurniati, dalam menyusun kebutuhan tenaga kesehatan ada beberapa metode yaitu keperluan kesehatan (health need method), kebutuhan kesehatan (Health services demand method), nilai (ratio method), dan sasaran upaya kesehatan yang ditetapkan (Health Service Targets Method). Sedangkan pada penelitian dijelaskan bahwa dibutuhkan perencanaan dengan memperhatikan kebutuhan dan beban kerja dalam menghitung kebutuhan tenaga kesehaatan di Puskesmas (L Paruntu et al., 2015).

Permasalahan kekurangan dan penyebaran tenaga kesehatan preventif dan kuratif di Puskesamas yang terjadi saat ini juga disebabkan karena keterbatasan anggaran pemerintah untuk melakukan pengadaan tenaga kesehatan melalui pengangkatan pegawai negeri sipil atau pengangkatan pegawai kontrak/honor, namun dengan adanya Peraturan Presiden Nomor 32 Tahun 2014 meyebutkan bahwa dana kapitasi dapat digunakan sebagai pembayaran jasa pelayanan kesehatan dan biaya operasional pelayanan kesehatan, memungkinkan pimpinan unit kerja untuk memanfaaatkan dana tersebut untuk pengadaan tenaga kesehatan kontrak di fasilitas pelayanan kesehatan yang dipimpinnya (Indonesia, 2014a).

Pada beberapa penelitian juga menyebutkan bahwa penerimaan dana kapitasi puskesmas merupakan pendapatan daerah dan dapat digunakan oleh puskesmas untuk membayar jasa pelayanan kesehatan di puskesmas dan dukungan operasional pelayanan kesehatan (Fitrianeti, Waris, \& Yulianti, 2017), (Anna, 2017). Dengan adanya kebijakan tersebut Kepala Satker dapat menggunakan dana kapitasi yang dihasilkan untuk mengatasi masalah kekurangan tenaga 
kesehatan di Puskesmas dengan memperhatikan aturan yang ada.

\section{Ketidakmerataan Sebaran Tenaga Kesehatan Khususnya di Wilayah Indonesia Bagian Tengah dan Timur}

Persebaran tenaga kesehatan di Puskesmas Indonesia selama ini lebih terkonsentrasi pada wilayah Indonesia bagian barat, karena wilayah barat Indonesia lebih dekat dengan Ibu kota negara, selain itu jumlah penduduk dan ketersediaan fasilitas, serta akses pelayanan kesehatan juga lebih mudah didapat. Wilayah Indonesia bagian timur masih banyak kekurangan Dokter Umum (Budijanto, 2015). Dilihat dari ketersediaan dan penyebaran tanaga kesehatan berdasarkan kondisi geografis serta ketersediaan fasilitas pelayanan kesehatan di wilayah Indonesia masih terkonsentrasi di pulau Jawa dan Bali (Idris, 2016).

Pemerintah melalui program kerja bidang kesehatan telah menetapakan prioritas untuk mengatasi masalah kesehatan di Indonesia antara lain; peningkatan status kesehatan dan gizi ibu anak, meningkatakan pengendalian penyakit, meningkatkan mutu dan layanan kesehatan terutama di daerah tertinggal, perbatasan, dan kepulauan terluar (DPTK) yang banyak terdapat di Indonesia bagian tengah dan timur, meningkatkan cakupan layanan kesehatan melalui sistim jaminan sosial nasional, terpenuhinya kebutuhan tenaga kesehatan, obat dan vaksin dan peningkatan responsivitas sistim kesehatan nasional (Kemenkes Republik Indonesia, 2015). Kurangnya tenaga kesehatan baik jumlah, jenis dan sebarannya menimbulkan dampak terhadap rendahnya akses masyarakat terhadap pelayanan kesehatan berkualitas.

WHO menyebutkan bahwa salah satu kunci keberhasilan dalam perencanaan, pengadaan dan penempatan tenaga kesehatan di negara angota Action For Global Health adalah perencanaan yang efektif, sistem pendidikan dan pelatihan, serta strategi retensi tenaga kesehatan. Sedangkan menurut Lehmann and Dussault, et al. retensi atau keputusan pegawai untuk menerima lokasi penugasan dipengaruhi beberapa faktor pendukung. Sarana dan prasarana pelayanan kesehatan, adanya dukungan finasial dan non finansial, faktor keamanan, kolegalitas dan kemudahan akses ke fasilitas sosial (Dieleman \& Harnmeije, 2006). Penelitian yang dilakukan di Australia tentang peningkatan jumlah tenaga kesehatan di daerah rural menyebutkan bahwa sistem perencanaan dan pengadaan tenaga kesehatan yang adequat dan transparan dapat membantu mengatasi masalah kekurang tenaga kesahatan di daerah rural (National Rural Health Alliance, 2008). Selain itu penelitian yang dilakukan Fendi dan Kurniati juga menyebutkan bahwa pemberian insentif baik finansial maupun non finansial pada tenaga kesehatan di daerah tertinggal berpengaruh terhadap faktor keinginan tenaga kesehatan untuk bekerja dan ditempatkan di wilayah yang dibutuhkan (Fendi \& Kurniati, 2013).

Pemerintah Pusat atau Daerah perlu memberikan perhatian khusus dalam sistim perencanaan dan pengadaan tenaga kesehatan di wilayah bagian Tengah dan Timur Indonesia. Selaian perencanaan yang ada adekuat dan transparansi proses rekrutmen. Adanya insentif, penyediaan fasilitas tempat tinggal, kendaraan, jaminan kesehatan dan keamanan juga merupakan faktor penting yang harus diperhatikan oleh Pemerintah, sehingga tanaga kesehatan yang ditempatkan mau melaksanakan tugas dan dapat bertahan di lokasi penempatan.

Adanya komitmen yang kuat dan tegas dari Pemerintah Daerah dalam melakukan redistribusi tenaga kesehatan di daerahnya, dengan memindahkan tenaga kesehatan yang berlebihan ke daerah yang kekurangan, seperti tertera dalam Keputusan Bersama Menteri Kesehatan, Menteri Dalam Negeri, Menteri Pendayagunaan Aparatur Negara dan Reformasi Birokrasi Tahun 2014 (Menteri, 2014).

Sistim penugasan khusus seperti Program Nusantara Sehat (NS) berbasis tim dan perorangan, Internship Dokter Indonesia dan Dokter Layanan Primer (DLP) yang diterapkan oleh Pemerintah Pusat bagi tenaga kesehatan juga diharapakan menjadi solusi untuk mengatasi masalah kekurangan dan penyebaran tenaga kesehatan yang tidak merata terutama daerah DTPK di wilayah Indonesia bagian Tengah dan Timur Indonesia (Kemenkes Republik Indonesia, 2015).

Lemahnya kontrol dan monitoring pemerintah terhadap suatu program kesehatan di Indonesia juga berdampak pada keberhasilan suatu kebijakan, sehingga dibutuhkan monitoring dan evaluasi secara berjenjang yang dilakukan oleh Pemerintah agar pelaksanaan kebijakan dapat mencapai tujuan dan dapat 
mengatasi masalah kesehatan. Pelaksanaan suatu kebijakan selalu di pengaruhi kondisi politik, ekonomi, sosial dan budaya di sutu tempat, sehingga dibutuhkan juga peran para pemangku kebijakan dalam membuat, melaksanakan dan evaluasi suatu kebijakan atau program kesehatan (Ayuningtyas, 2018).

\section{KESIMPULAN DAN SARAN}

Kondisi tenaga kesehatan yang didayagunakan di Puskemas Indonesia saat ini masih mengalami ketidakmerataan (inequality) dalam jumlah dan sebarannya. Berdasarkan ratio jumlah tenaga kesehatan di Puskesmas Indonesia belum memnuhi kebutuhan penduduk Indonesia yang besar jumlahnya. Berdasarkan penyebaran tenaga kesehatan di Puskesmas Indonesia lebih terkonsentrasi di wilayah Indonesia bagian barat di bandingkan wilayah tengah dan timur, hal ini disebabkan karena jumlah penduduk yang lebih banyak dan fasilitas kesehatan di wilayah Indonesia bagian barat lebih lengkap dibandingkan wilayah bagian tengah dan timur Indonesia, sehingga hal tersebut dapat menghambat pembangunan kesehatan yang bertujuan untuk memberikan pelayanan berkualitas yang adil dan merata bagi seluruh rakyat Indonesia.

Pemerintah baik Pusat maupun Daerah harus memperhatikan kebutuhan masyarakat dan transparan dalam perencanaan dan pengadaan tenaga kesehatan. Selain itu Pemerintah juga perlu memperhatikan faktor retensi tenaga kesehatan terutama faktor kesejahteraan para tenaga kesehatan yang akan ditempatkan di wilayah DTPK berupa insentif, fasilitas tempat tinggal, jaminan kesehatan dan keamanan sebagai bentuk penghargaan bagi tenaga kesehatan.

Adanya kebijakan dari Pemerintah Daerah untuk memberikan beasiswa kepada para putra/putri daerah agar dapat sekolah dan meningkatkan kompetensi dibidang kesehatan, sehingga dapat memperkuat sumber daya bidang kesehatan di daerah. Meningkatkan pendayagunaan lulusan sekolah tinggi kesehatan untuk menanggulangi masalah maldistribusi dan meningkatkan kompetensi dalam memberikan pelayanan kesehatan dengan program ikatan dinas.

Dengan adanya kemajuan teknologi dan kemudahan akses internet, pelayanan kesehatan untuk daerah dengan keterbatasan tenaga kesehatan dapat dilakukan dengan sistim pelayanan kesehatan berbasis e-health. Konsultasi pelayanan kesehatan dapat dilakukan secara efektif dan efesien dengan tenaga ahli kesehatan jarak jauh mengunakan internet.

\section{DAFTAR PUSTAKA}

Anna, A. (2017). Analisis Pemanfaatan Dana Kapitasi Jaminan Kesehatan Nasional di Puskesmas Bromo Kecamatan Medan Denai Kota Medan Tahun 2017.

Ayuningtyas, D. (2018). Analisis Kebijakan Kesehatan Prinsip dan Aplikasi. Depok: Rajawali Pers.

BPJS. (2016). Panduan Praktis Gate Keeper Concept (Faskes BPJS Kesehatan). Jakarta: BPJS.

BPS. (2018). Statistik Indonesia, 2018. Retrieved from https://www.bps.go.id/

Budijanto, D. (2015). Puskesmas di Indonesia (Analisis Implementasi Permenkes No . 75 tahun 2014) Adequacy of Strategic Health Centre In Indonesia, (75), 179186.

Dieleman, M., \& Harnmeije, J. W. (2006). Improving health worker performance: in search of promising practices. Journal of Interventional Radiology (China). Netherland. https://doi.org/10.3969/ j.issn.1008-794X.2018.04.019.

Fendi, F., \& Kurniati, A. (2013). Review Sistematis Peningkatan Retensi Tenaga Kesehatan di Daerah Tertinggal. Jurnal Sistem Informasi MTI-UI, 6(1), 64-73.

Fitrianeti, D., Waris, L., \& Yulianti, A. (2017). Penganggaran dan Penerimaan Dana Kapitasi Program JKN di Daerah Terpencil Kabupaten Kepulauan Mentawai Implementation of Breaching And Acceptance Of Health Capitation Funds National Health Care Program In Remote Areas Of Distric Mentawai Islands. Jurnal Penelitian Dan Pengembangan Pelayanan Kesehatan, 1(2), 92-101.

Idris, H. (2016). Ekuitas Terhadap Akses Pelayanan Kesehatan: Teori \& Aplikasi Dalam Penelitian Equity of Acces to Health Care: Theory \& Aplication in Reserch, 7, 73-80.

Indonesia. Peraturan Presiden Republik Indonesia Nomor 72 Tahun 2012 Tentang Sistim Kesehatan Nasional (2012). 
Indonesia. Peraturan Presiden Nomor 32 Tahun 2014, tentang Pengelolaan dan Pemanfaatan Dana Kapitasi Jaminan Kesehatan Nasional Pada Fasilitas Kesehatan Tingkat Pertama Milik Pemerintah Daerah (2014).

Indonesia. Undang-undang Nomor 36 Tahun 2014, Tentang Tenaga Kesehatan (2014).

Indonesia, D. Undang-Undang Nomor 36 Tahun 2009, tentang Kesehatan (2009).

Kemenkes Republik Indonesia. Keputusan Menteri Kesehatan RI Tentang Pedoman Penyusunan Perencanaan SDM (2010).

Kemenkes Republik Indonesia. (2011). Rencana Pengembangan Tenaga Kesehatan Tahun 2011 - 2025.

Kemenkes Republik Indonesia. Permenkes Nomor 75/2014 tentang Puskesmas (2014).

Kemenkes Republik Indonesia. (2015). Rencana Strategis Kementerian Indoneisa 2015-2019. Retrieved from http://www.depkes.go.id/article/

Kemenkes Republik Indonesia. Peraturan Pemerintah Republik Indonesia Nomor 47 Tahun 2016 Tentang Fasilitas Pelayanan Kesehatan Dengan (2016).

Kemenkes Republik Indonesia. (2018). Data tenaga kesehatan yang diberdayagunakan di Puskesamas Indoneisa. Retrieved from http://bppsdmk.kemkes.go.id/info_sdmk/ info/distribusi_sdmk_pkm

Kepala Badan PPSDM Kesehatan. (2017). Program Pemenuhan Tenaga Kesehatan. Paparan Rakerkesnas. Retrieved from http://depkes.go.id/resources/download/b ahan_rakerkesnas_2017/Badan PPSDM Kesehatan.pdf

Kurniati, A. (2017). Kajian Sumber Daya
Manusia Kesehatan di Indonesia. https://doi.org/10.13140/RG.2.1.1440.68 04

L Paruntu, B. R., M Rattu, A. J., Tilaar, C. R., Kesehatan Kabupaten Minahasa, D., Ilmu Kesehatan Masyarakat Universitas Sam Ratulangi Manado, F., Pascasarjana Universitas Sam Ratulangi Manado, P., \& Kunci, K. (2015). Perencanaan Kebutuhan Sumber Daya Manusia di Puskesmas Kabupaten Minahasa Human Resource Requirements Planning in Health Center Minahasa District. JIKMU, 5(No. 1, Januari 2015), 43-53.

Menteri, K. B. (2014). Perencaan dan Pemerataan Tenaga Kesehatan di Fasilitas Pelayanan Kesehatan Milik Pemerintah Daerah.

Mujiyati, Y. Y. (2016). Ketersediaan Sumber Daya Manusia Kesehatan pada Fasilitas Kesehatan Tingkat Pertama dalam Era Jaminan Kesehatan Nasional di Delapan Kabupaten-Kota di Indonesia. Litbangkes Badan, Ri Kemenkes, (75), 201-210.

National Rural Health Alliance. (2008). Improving the rural and remote health workforce. Deakin West.

Nurhayati, M. (2016). Peran Tenaga Medis dalam Pelayanan Kesehatan Kabupaten Kutai Barat. EJournal Llmu Administrasi Negara, 4(1), 2127-2140.

Wulandari, F. K., \& Achadi, A. (2016). Analisis Karakteristik dan Persepsi Pengguna Pelayanan Terhadap Pemanfaatan Puskesmas Sebagai Gatekeeper di Dua Puskesmas Kota Bekasi Tahun 2016. Jurnal Ekonomi Kesehatan Indonesia, 2(1), 39-4. https://doi.org/10.1002/stem.438. 